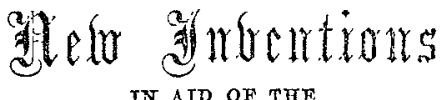

\section{PRACTICE OF MEDICINE AND SURGERY.}

\section{THE BRITISH FEEDING-BOTILE FOR INEANTS}

consists of a feeding-bottle of the usual form, with an electroplated tube, and a regulating cock attached to it. The following are some of the advantages which it appears to possess:

It may be placed in any position withont the food ruming out.

The supply of food can be regulated witi a stop-cock while the infant is taking food, withont removing the teat from the mouth, so that biscuit-food, or a single drop of milk, may be passed through, or the supply can be immediately stopped.

Being electro-plated on white metal, it may be instantaneously cleaned by washing in water.

Unlike wood, ivory, or bone, it is impervious to moisture, and cannot become sour.

There is no possibility of the infant drawing air with the food.

The whole is so simple that a child may be momentarily instructed how to use it.

This bottle is the invention of $\mathrm{Mr}$. W. Cooper, chemist, Oxford-street.

\section{POTTER'S LEECH AQUARIUM}

THE peculiarity of this aquarium consists in the introduction of a bed of Smyrna clay at the bottom of the vessel. In this are inserted some water plants; and as the clay is the native earth of the leech, it buries itself in the loam, where it remains in a state of health. A great number of these vessels are in use, and are found to succeed admirably.

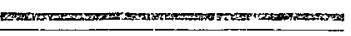

\section{ALIEGED MALPRACTICE IN MIDWIFERY. To the Eutitor of THE LANCET.}

SIR, - In the spirited and soul-stirring editorial article of last week's LANCET, on the vindication of the profession arainst the verdicts of ignorant and incompetent jurymen, there appears a slight inaccuracy which I am sure you will readily permit me to rectify. The last few lines of the article in question, at page 528, run thus: "That the decision of the jury was the result of prejudgment is clear from this fact, that, having heard the adverse testimony of Mr. Smith and Mr. Garrington, they protested against hearing Mr. Wiblin," \&c. I am gratified to say that Mr. Garrington gave no adverse testimony; on the contrary, he came forward like a man, and coincided with all who brought to bear upon the case a truthful and unprejudiced mind; and he not only pressed his opinion that the woman died of child-bed fever, but he volunteered the statement that a patient of his own had died six days after her confinement in an adjoining street; and I am further informed that Mr. Garrington has lost another patient, from low fever, in the very next street to that in which Mary Berry died. Mr. Garrington's evidence is all-important; his sound reasoning and deductions at the post-mortem examination, and his subsequent evidence before the coroner, gave evidence of a masterly and truthful mind, and of the career of a practitioner of a very high order.

Since the coroner's inquest on Mary Berry, I have received several letters warmly expressive of sympothy towards $\mathrm{Mr}$. Rolph; and amongst others, one from my friend Dr. Pardey of this town, and another from Dr. Buckell of Chichester, to Mr. Rolph. These two last are of a most interesting character, and I trust you will think with me that they are deserving of record in THE LANCET.

I am, Sir, your obedient servant,

Southampton, Nov, 23rd, 18507 . JOHN WIRLIN, F.R.C.S.

My DEAR WIBLIN, - In reply to your note, I beg to send you the following particulars:-

In the year 1853 , I was called to attend Mary Hale, living at Robert Town, near Leeds. She had been at that time three 554 days in labour, under the care of a midwife. On examination I found the cause of delay was a transverse presentation, the arm lying in the vagina, and the woman excessively exhausted. After administering stimulants, I succeeded in turning and delivering the child. Some slight hæmorrhage followed, and the placenta was found to be firmly adherent to the uterus. The funis was softened and brittle, and cameaway with very slight traction.

After waiting nearly an hour, an attempt was made to deliver by introducing the hand, but such alarming faintness was produced that it was necessary to desist. I waited another hour, administering stimulants and beef-tea freely, and then made a second attempt, with the same result. It was now evident that to attempt further to complete the labour would in all probability, be immediately fatal, and I determined to leave the placenta.

The patient from this time was supported by liberal diet, and the administration of ammonia and opium at first, followed by quinine and opium. On the third day the discharges became offensive, and the vagina and uterus were regularly syringed with tepid water until the tenth day, when the placenta came away. The woman had no excessive hæmor rhage at any time, but presented a singularly anæmic and bloodless appearance soon after the labour, and had an attack of low fever which lasted a month. She eventually recovered, and was living and well when $I$ left Yorkshire.

I am, Sir, faithfully yours,

Southampton, Nov. 23*d, 1857. Ciras. Parday, M.B.

North Pallant, Chichester, Nov. 20th, 1857.

DEAR Sur,-Only having seen one side of the unfortunate case in which you are so painfully involved, I do not know whether the following case would be of any service to you, or has any bearing upon it:-

Mrs. D__ has had several children, and was again confined about ten elays ago, about eight A. M. ; labour natural ; placenta came away under the nsual circumstances. I called in the middle of the day; she complained of a good deal of pain in the abdomen, to which I did not attach much importance. The next day (about thirty hours after confinement) when I called, the nurse told me she had been in a great deal of pain all night, and then produced the chamber utensil to show me something that had passed. It was about two-thirds the size of the placenta, and in colour and membranous appearance loolived like the unattached surface of the placenta, with a coil of plice on the upper surface, which, looking at it in the vessel, might easily have been mistaken for a tiny cord lying on the surface. The membranous sac was complete, and upon opening it, was found to contain only a dark-coloured, firm, Jloody coagulum, filling its entire cavity. Upon washing the contiining membrane, it had the usual appearance of the outer membrane of the ovum. I think it might easily have been mistaken for a small placenta. It was probably a blighted ovum.

$$
\text { Dr. Rolph, Portsmouth. Yours truly, }
$$

** We regret having coupled the name of Mr. Garrington with that of Mr. Smith in the article referred to. Mr. Garrington's evidence was that of an experienced and sound practitioner; it would, therefore, be an injustice to him not to correct the misstatement as to his evidence. Have the practi. tioners who condemned a brother under very trying circumstances, and which ought to have enlisted upon his side the sympathy of every man in the profession, ever asked themselves this question: If the placenta had been detached by force from the walls of the uterus by Mr. Rolph, and his patient had died from the injury he had inflicted by that proceeding, would not they have been equally loud in their denunciations against their brother townsman for reckless and unauthorised practice? Is the party-feeling in Portsmouth so strong amongst the medical practitioners as to seek for opportunities for the ruin of a professional brother? We cannot believe this. But we must protest, in the name of the profession and of the public, against the evidence of the adverse witnesses in Mr. Rolph's case. Mr. Rolph is a man of high attainments, one of the most successful practitioners of midwifery in the connty; and we cannot regard the most unwarrantable attempt to injure his reputation but as an attack upon the medical profession itself. -ED. L. 